\title{
Microscopic Behavior on the Protection of Polyacrylonitrile- Based Carbon Fibers from Thermal Oxidation
}

\author{
Donghwan CHO, ${ }^{\dagger}$ Byung Il Yoon, ${ }^{*}$ Hun Seung HA, ${ }^{*}$ and Yun Soo Lim** \\ Department of Polymer Science and Engineering, Kumoh National University \\ of Technology, Kumi, Kyungbuk 730-701, Korea \\ * Composite Materials Lab., Agency for Defense Development, \\ P.O. Box 35, Taejon 305-600, Korea \\ ** Department of Inorganic Materials Engineering, Myong Ji University, \\ Yongin, Kyunggi, Korea
}

(Received December 2, 1996)

\begin{abstract}
The surface of polyacrylonitrile-based carbon fiber was appropriately coated with dilute phosphoric acid to protect or retard its thermal oxidation occurring during an exposure to high temperatures above $600^{\circ} \mathrm{C}$ in air. Microscopic behavior on surface damage and size change in the uncoated and coated fibers was compared using thermogravimetric and scanning electron microscopic techniques. The result showed that the state of the carbon fiber surface was found to be remarkably improved by the coated phosphorous compound, minimizing the surface pitting, and size reduction of carbon fiber by high temperature oxidation. The microscopic evidence for the effective protection of carbon fiber from thermal oxidation also indicated that use of this technology may be positively considerable to other related materials.

KEY WORDS Carbon Fiber/Thermal Oxidation Protection/ Microscopic Behavior / Phosphorous

Compound /
\end{abstract}

Carbon fibers are extremely important in the application of carbon fiber related materials, especially carbon fiber-reinforced polymer, ceramic or metal composites, and carbon-carbon composites. They have been widely used as a key component of advanced composite materials in aircraft, aerospace, and missile applications, experiencing high temperature aerial environments. However, because carbon fibers exposed to high temperatures for a long duration above $500^{\circ} \mathrm{C}$ are extremely sensitive to oxygen, use of carbon fiber-reinforced composite materials under very high temperature conditions in air has been often restricted in practical performances. ${ }^{1-3}$ It is very clear that if the strong interfacial bonding between the fiber and matrix in the composite and the fibrous reinforcement itself are damaged and weakened by severe thermal oxidation, resulting in debonding at the interfaces, then a serious deterioration of various properties in the composite would be unavoidable. Due to significant influence of the thermal response of carbon fiber on various properties of the related composite materials, oxidation is one of major limiting factors in determining the lifetime and performance of carbon fibers and their composites in many applications. Therefore, many researches to investigate the oxidative phenomenon of carbon materials have been driven over the last decade. ${ }^{4-7}$

Phosphorous compounds are well-known as one of the materials contributing to the antioxidation and flame resistance of various organic materials including carbon. ${ }^{8-10}$ Some researches to improve the oxidation protection of carbon-based materials using phosphorous compounds have been progressed. ${ }^{11-14}$ During the pyrolysis of a carbon-based composite material a significant quantity of oxygen can penetrate into the inner region of the composite through the resultant enlarged

\footnotetext{
† Author to whom all correspondence should be addressed.
}

pores. It can be proposed that at this step the phosphorous compound may preferentially react with oxygen atoms rather than carbon atoms in the carbon fibers (or in the carbon matrix in the case of carbon-carbon composite), form stable complexes at the active sites and then reduce the oxidation of the substrate exposed to a high temperature environment.

In general, there have been many work on increasing the interfacial bonding between the fiber and matrix in the composite and on enhancing its mechanical property by surface-treatment of carbon fiber using various techniques. ${ }^{15-17}$ However, the report on the surface coating of carbon fiber for the purpose of increasing high temperature oxidation resistance of carbon fiber-reinforced composite materials has been rarely found. Consequently, the aim of the present study is to improve the thermal oxidation protection of carbon fibers exposed to different heat-treatment temperatures by using carbon fibers coated with a dilute phosphoric acid solution and also to show microscopic evidence on the apparent protection of carbon fibers from severe surface damage and size reduction by thermal oxidation.

\section{EXPERIMENTAL}

\section{Materials}

High-strength polyacrylonitrile (Pan)-based carbon fibers with 3000 filaments manufactured by Tae Kwang Industries Co. were used throughout this study. The fiber was surface-treated and unsized. The average diameter of a single filament of the carbon fiber was $6.8 \mu \mathrm{m}$. The fiber density was $1800 \mathrm{~kg} \mathrm{~m}^{-3}$. Phosphoric acid $\left(\mathrm{H}_{3} \mathrm{PO}_{4}\right)$ of an extra pure grade purchased from Duk San Chemical Co. was used for the purpose of the inhibition or retardation of carbon fiber oxidation during heat-treatment. Phosphoric acid was used with different concentrations of $0-4.0 \mathrm{vol} \%$ in methanol. Methanol was purchased 
from Merck Chemical Co.

\section{Fiber Preparations}

The surface of carbon fiber was homogeneously coated with phosphoric acid of each given concentration, as follows. 1) Cut the as-received carbon fiber in 25$30 \mathrm{~cm}$ size. 2) Fix each end of the fiber tow with the tape to prevent the pull-out of each filament. 3) Prepare dilute mixtures with different concentrations of phosphoric acid in $50 \mathrm{ml}$ methanol. 4) Immerse each fiber tow in each mixture for a sufficient period of time. 5) Dry the prepared fiber tow in the oven for $3-4 \mathrm{~h}$ at $150^{\circ} \mathrm{C}$. As-received carbon fiber tows were used as the uncoated sample without any modification.

\section{Heat Treatment and Microscopic Observation}

Among the samples prepared, the carbon fiber coated with $0.5 \mathrm{vol} \%$ phosphoric acid and the uncoated carbon fiber were respectively heat-treated at different temperatures of $656,770,821$, and $910^{\circ} \mathrm{C}$ in air using a thermogravimetric apparatus (Dupont 951 TGA). The heating rate was $10^{\circ} \mathrm{C} \mathrm{min}^{-1}$ throughout this work. Each sample was cooled down without holding time right after reaching the final temperature. The microscopic behavior of the samples exposed to different heat-treatment temperatures was thoroughly examined using a scanning electron microscope (SEM, JXA-840, JEOL). An energy dispersive $X$-ray spectroscopic technique (EDS) in the SEM was also utilized to analyze the elements existing on the surface of carbon fiber after each heat-treatment.

The averaged diameter of a single fiber filament for the uncoated and coated carbon fibers before and after heat-treatment was measured with a calliper from the magnified scanning electron micrographs observed at many different locations of the fibers.

\section{RESULTS AND DISCUSSION}

\section{Effect of Phosphoric Acid on the Thermal Stability of Carbon Fibers}

Figure 1 shows TGA thermograms in air for the uncoated and coated carbon fibers. The efect of the coating concentration on the thermal stability of the fiber can be clearly explained. Above $600^{\circ} \mathrm{C}$, the thermal stability or oxidation resistance of the coated fibers was found to be better than that of the uncoated one. Just before a complete oxidation (almost $100 \%$ burn-off), the temperature difference between the uncoated and coated samples was about $100^{\circ} \mathrm{C}$. However, in the case of the carbon fiber coated with more than $2.0 \mathrm{vol} \%$ phosphoric acid, there was no significant improvement on the thermal stability above $600^{\circ} \mathrm{C}$ in comparison with the case coated with $0.5 \mathrm{vol} \%$. It was rather observed that some coated fibers showed more weight loss than the uncoated one below $600^{\circ} \mathrm{C}$. The reason is that in the case of more than $2.0 \mathrm{vol} \%$ the phosphoric acid remaining on the fiber surface after drying gradually converts into pyrophosphoric acid $\left(\mathrm{H}_{4} \mathrm{P}_{2} \mathrm{O}_{7}\right)$ around $200^{\circ} \mathrm{C}$ and into metaphosphoric acid $\left(\mathrm{HPO}_{3}\right)_{n}$ above $300^{\circ} \mathrm{C}$ with some volatiles resulting in a slight weight loss. It can be, therefore, stated that the concentration of more than $2.0 \mathrm{vol} \%$ was not appropriate to protect carbon fiber from thermal oxidation, considering some processing drawbacks which might be

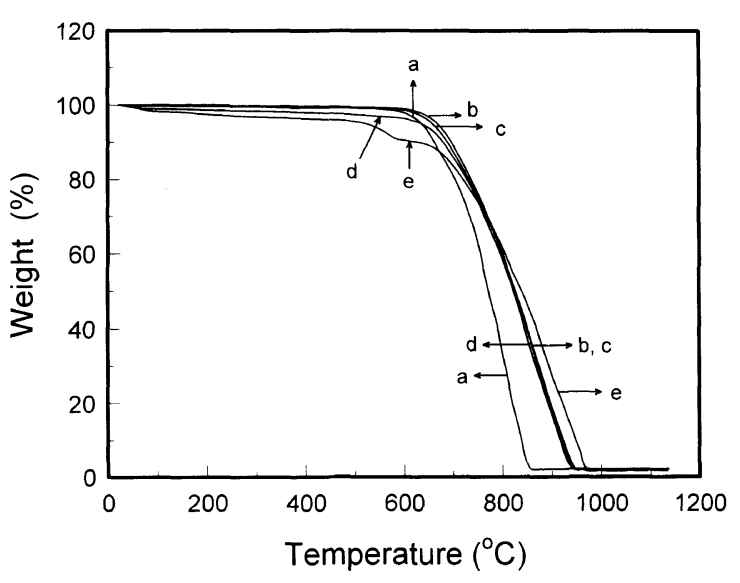

Figure 1. TGA thermograms in air showing the effect of different concentrations of phosphoric acid coating on the thermal stability of carbon fiber: a, $0 \%$; b, 0.5\%; c, $1.0 \%$;, $2.0 \%$; e, $4.0 \%$.

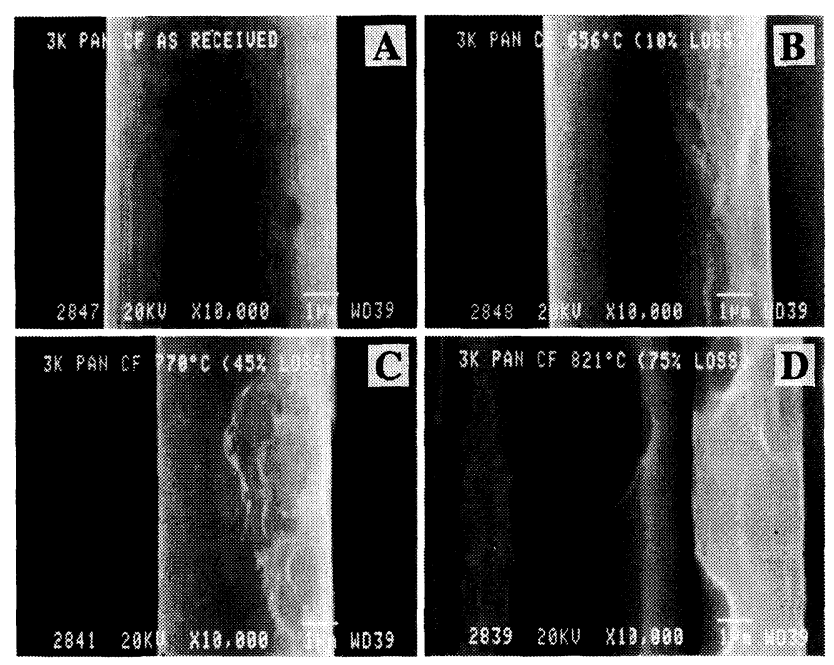

Figure 2. Scanning electron micrographs representing the change in diameter and shape of the uncoated carbon fibers by thermal oxidation during an exposure to different temperatures in air. A, as-received; B, $656^{\circ} \mathrm{C} ; \mathrm{C}, 770^{\circ} \mathrm{C} ; \mathrm{D}, 821^{\circ} \mathrm{C}$.

caused during the fabrication of carbon fiber-reinforced composite material. There was an overally similar thermal stability between the two fibers coated with 0.5 and $1.0 \mathrm{vol} \%$ of phosphoric acid. It is reasonable that the lower level of phosphoric acid as a coating ingredient may be desirable for minimizing the deterioration of the interfacial and mechanical properties in the related composite which might be occurred. Additionally, the excessive quantity of phosphoric acid may provide some causes for catalyzing the cure of resin matrix, decreasing the flexibility of prepreg, and further making a certain difficulty on the fabrication of the related composite. Accordingly it is worthy of examining the microscopic behavior in the carbon fiber before and after oxidation, based upon the result of the thermal stability for the coated fiber with $0.5 \mathrm{vol} \%$ phosphoric acid only.

\section{Microscopic Evidence of the Oxidation Protection of Carbon Fibers}

Figure 2 shows the SEM result representing the change in diameter and shape of the uncoated carbon fibers by thermal oxidation at different heat-treatment temperatures. After heat-treatment at $656^{\circ} \mathrm{C}$ (Figure 2B), the 
Table I. A comparision of changes in the fiber diameter between the uncoated and coated carbon fibers exposed to different heat-treatment temperatures in air

\begin{tabular}{cccccc} 
Temperature & \multicolumn{2}{c}{ Fiber diameter $/ \mu \mathrm{m}$} & & \multicolumn{2}{c}{ Diameter reduction $/ \%$} \\
\cline { 1 - 2 } \cline { 5 - 6 }${ }^{\circ} \mathrm{C}$ & Uncoated & Coated & & Uncoated & Coated \\
\cline { 5 - 6 } No HT & 6.70 & 6.96 & & 0 & 0 \\
656 & 6.43 & 6.72 & & 4.0 & 3.4 \\
770 & 4.94 & 5.57 & & 26.3 & 20.0 \\
821 & 3.16 & 5.05 & & 52.8 & 27.4 \\
910 & - & 2.99 & & - & 57.0
\end{tabular}

as-received fiber (Figure 2A) exhibited about $10 \%$ weight loss, the fiber diameter slightly decreased and the surface began to be influenced showing small damage by oxidation. At $770^{\circ} \mathrm{C}$ (Figure $2 \mathrm{C}$ ), the diameter largely decreased and the damaged region in the fiber increased. The weight loss at this temperature was about $45 \%$. At $821^{\circ} \mathrm{C}$ (Figure 2D) where the weight loss of about $75 \%$ proceeded, the diameter seriously decreased up to about $3 \mu \mathrm{m}$ and the damage by oxidation was very profoundly distributed over all the surface. Such a microscopic phenomenon on the thermal oxidation of carbon fiber agrees with the result seen in the previous study. ${ }^{18}$ The result also indicates that a tendency of the fiber damage by oxidation is initiated from the outer region of the fiber, as demonstrated in Figure 2B. It can be easily expected from the case of Figure 2D that the role of carbon fiber as a reinforcement in fiber-reinforced composite material will be significantly weakened due to the serious deterioration of the fiber surface and diameter above $800^{\circ} \mathrm{C}$.

Table I represents the variation of the fiber diameter in the uncoated and coated carbon fibers exposed to different heat-treatment temperatures in air. It was found that the diameter of the uncoated fiber greatly reduced after $700^{\circ} \mathrm{C}$ and exhibited a size reduction of more than $50 \%$ above $800^{\circ} \mathrm{C}$. At the most severely damaged area where many parts of the fiber surface were pitted, the size reduction was observed up to $70-80 \%$ of the original fiber diameter.

Figure 3 is for the coated samples according to heattreatment temperature. Here, a typical behavior of thermal oxidation as seen in Figure 2 was not observed at all through an overall inspection regardless of heattreatment temperature. The coated fiber surface was not pitted over all the surface, even though there was only a slight reduction in the fiber diameter near $800^{\circ} \mathrm{C}$, which was much less reduced than in the uncoated one. As a result, Figure 3 provides the visual evidence showing the effective protection of thermal oxidation by a phosphoric acid coating on the carbon fiber surface. The reason for which the surface state of the coated carbon fiber even after high temperature oxidation does not change without any pitting and the fiber diameter shrinks somewhat may be explained by the following two mechanisms. First, it has been known that Panbased carbon fiber exhibits the cross-sectional microstructure, called a sheath-core structure with basal plane aligned parallel to the fiber surface, consisting of microfibrillar and lamellar forms. ${ }^{19}$ Intermediate modulus Pan-based carbon fibers as used in the present work

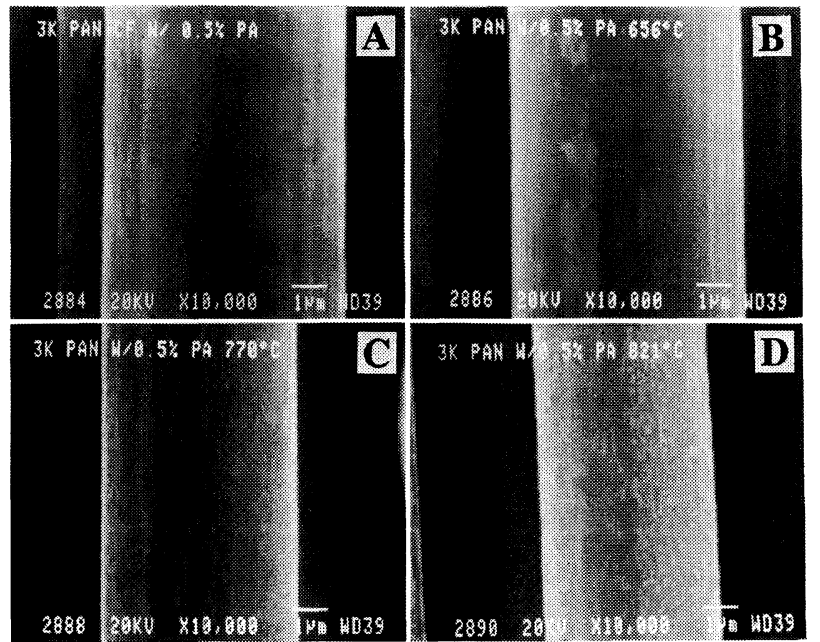

Figure 3. Scanning electron micrographs representing the oxidation protection in the $\mathrm{H}_{3} \mathrm{PO}_{4}$-coated carbon fibers exposed to different temperatures in air. A, as-received; $\mathrm{B}, 656^{\circ} \mathrm{C} ; \mathrm{C}, 770^{\circ} \mathrm{C} ; \mathrm{D}, 821^{\circ} \mathrm{C}$.

also have a highly contorted transverse graphene layers structure, exhibiting a sheath-like form in the outer layers of the fiber. The degree of misalignment of a crystalline plane increases with depth into the fiber. The outer layer may be more sensitive to the surrounding temperature than the inner layer and then gradually denuded with severity of oxidation. Perhaps, it makes possible to resize the carbon fiber to smaller diameter by uniform surface oxidation, as insisted by some other work ${ }^{6,20}$ Second, competitively the phosphorous compound coated on the fiber surface may be able to transversely diffuse or migrate into the inner layer of a filament through misaligned sheath layers and microstructural flaws and cracks existing in the carbon fiber with increasing temperature. From the previous study ${ }^{13}$ for stabilized Pan fibers, it was also found that the transverse diffusion or migration occurs from the exterior to the interior of a filament. The phenomenon was most active up to about $1-2 \mu \mathrm{m}$ from the exterior, gradually decreasing through the diameter of fiber. Such results indicate that the diffused phosphorus somewhat contributes to retarding possible reactions with oxygen by blocking many active sites.

Interestingly it was observed that white grains or spots were uniformly scattered in the fiber surface, as seen in Figures $3 \mathrm{C}$ and 3D. They became more distinct with an increase of heat-treatment temperature. These grains were anticipated to be by phosphorus. As mentioned earlier, phosphoric acid may transform into poly(phosphoric acid) through pyrophosphoric acid and metaphosphoric acid with increasing temperature. Above the degradation temperature it converts into solid phosphorus, which is thermally stable above $600^{\circ} \mathrm{C}$, forming network structures. ${ }^{21}$ This may result in the generation of discontinuous microscopic protective layer or barrier. The inorganic compound may preferentially react with the oxygen atoms introduced in the carbon fiber and shield the active sites forming stable complexes. A qualitative explanation for identification of the component follows. Figure 4 shows the SEM photos for the coated carbon fiber heat-treated at $910^{\circ} \mathrm{C}$ in air. No surface damage was observed, but the fiber diameter significantly 

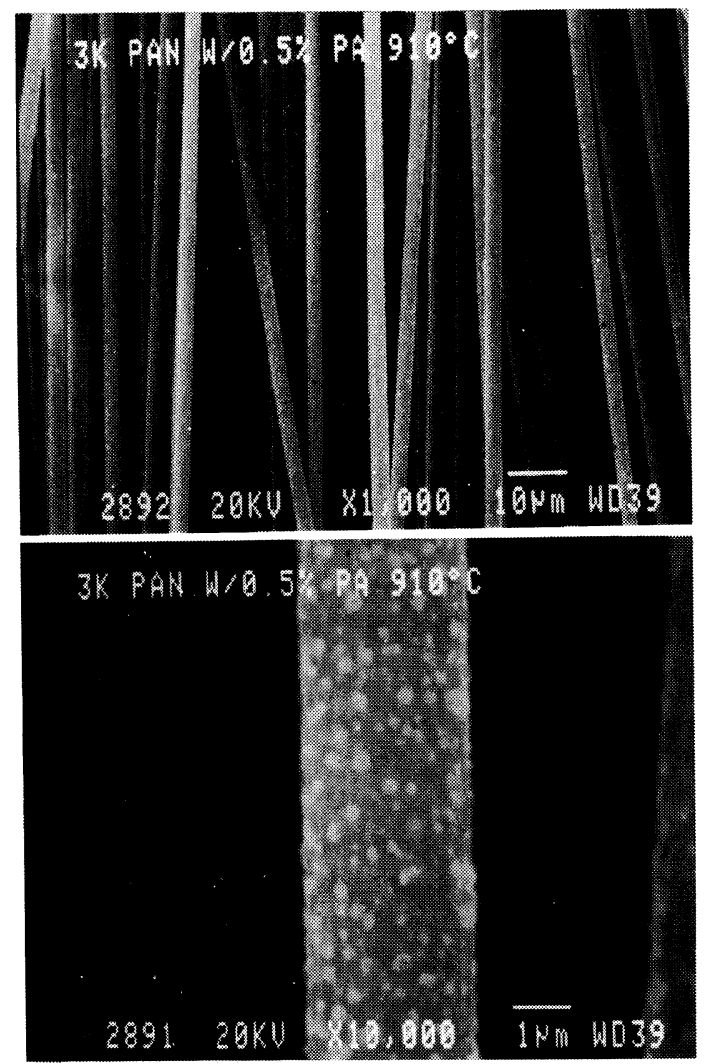

Figure 4. Scanning electron micrographs of the coated carbon fiber exposed to $910^{\circ} \mathrm{C}$ in air. (top, $\times 1000$; bottom, $\times 10000$ )

decreased up to about $3 \mu \mathrm{m}$ due to the more severe oxidation condition. The white grains on the surface were obviously distinguishable. An energy dispersive Xray spectroscopy was performed to identify these grains in the longitudinal region of the coated fiber. The result is shown in Figure 5. It was found that there was no significant change in the peak intensity which was identified as phosphorus in the samples heat-treated at lower temperatures, but the peak became more distinct in the samples heat-treated at higher temperatures. The reason for the gradual increase of the phosphorus $(\mathrm{P})$ peak at $2.01 \mathrm{keV}$ is that as active oxidation and fiber shrinkage take place in the coated carbon fiber, the relative quantity of phosphorus remaining on the fiber surface per unit area at the identical microscopic magnification becomes larger with increasing heat-treatment temperature.

The variation of the fiber diameter change in the coated sample with heat-treatment temperature is also represented in Table I. There was no change up to $600^{\circ} \mathrm{C}$. It was observed below $600^{\circ} \mathrm{C}$ that the diameter of the coated fiber was thicker about $0.2-0.3 \mu \mathrm{m}$ than that of the uncoated fiber because of the coating thickness of about $0.1-0.15 \mu \mathrm{m}$ by phosphoric acid. A comparison between the results for the uncoated and coated samples in the Table I and Figure 3 give a very positive meaning for the effective protection of carbon fiber from thermal oxidation by a phosphoric acid coating. The size reduction of the fiber at $821^{\circ} \mathrm{C}$ was only about $27 \%$ (ca. $5 \mu \mathrm{m}$ retention of the original size). This was only half of the value reduced for the uncoated one. In other words, it turns out that the reduction of the diameter in the coated fibers exposed to $821^{\circ} \mathrm{C}$ in air was similar with the result in the uncoated fibers exposed to $770^{\circ} \mathrm{C}$. This reduction

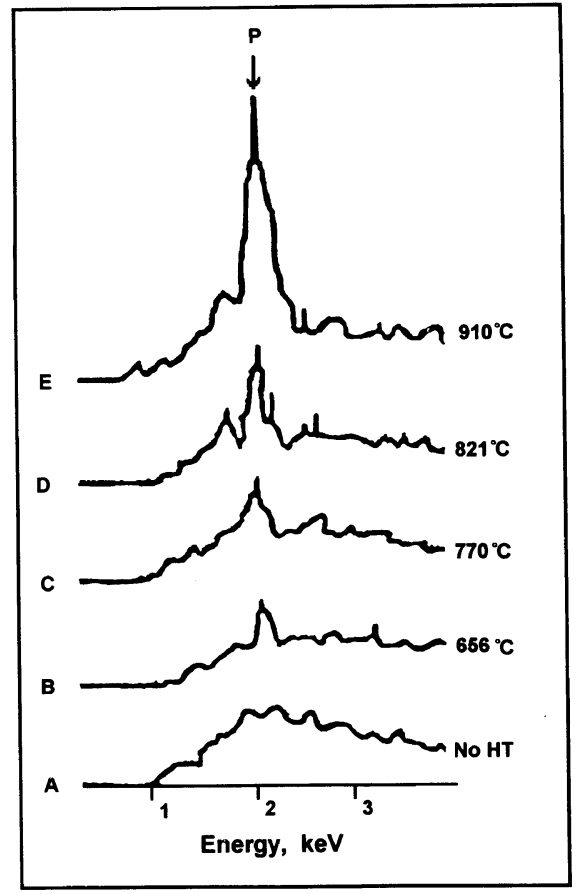

Figure 5. Variations of the EDS intensity for the surface of $\mathrm{H}_{3} \mathrm{PO}_{4}$ coated carbon fiber exposed to different temperatures.

in the fiber size is mainly responsible for the weight loss in the TGA thermogram seen in Figure 1. It is also believed that the prevention of the fiber pitting and the retardation of the fiber size reduction by the surface coating significantly contribute to the thermal stability of carbon fiber especially at higher temperatures.

The effect of a phosphoric acid coating to improve the thermal resistance of carbon fiber becomes more remarkable with increasing temperature. Importantly it suggests that if the coating technology proposed here becomes practical in high temperature applications around $800^{\circ} \mathrm{C}$ under an open environment, the use temperature of carbon fiber-reinforced composite materials would be enhanced much. As fiber reinforcement is a predominant factor in determining thermal, physical, ablative and mechanical properties of fiber-reinforced composite materials, being strongly dependent of the feature of the fiber surface, the significance will be surely more emphasized.

\section{CONCLUSIONS}

1. A phosphoric acid coating on the Pan-based carbon fiber surface to improve its thermal oxidative stability above $600^{\circ} \mathrm{C}$ was studied at different concentrations.

2. In comparison with the uncoated carbon fibers, the coated fibers with $0.5 \mathrm{vol} \%$ phosphoric acid was effectively protected from the serious deterioration of the fiber surface and size by oxidation which can be occurred during an exposure to different heat-treatment temperatures in an aerial environment. The microstructural evidence well supported the fact.

3. The result from the present study would give the positive effect not only on the oxidation resistance in carbon fiber-reinforced composite materials but also on their thermal, mechanical, and ablative performances 
under high temperature conditions of an open environment.

\section{REFERENCES}

1. K. M. Prewo and J. A. Batt, J. Mater. Sci., 23, 523 (1988).

2. S M. Bleay and V. D. Scott, Carbon, 29, 871 (1991).

3. A. Paillous and C. Pailler, Composites, 25, 287 (1994).

4. D. W. McKee, C. L. Spiro, and E. J. Lamby, Carbon, 22, 285 (1984).

5. L. E. Jones and P. A. Thrower, "Extended Abstracts 18th Biennial Conference on Carbon," American Carbon Society, San Diego, 1987, p 468.

6. V. Z. Shemet, A. P. Pomytkin, and V. S. Neshpor, Carbon, 31, 1 (1993).

7. R. G. Iacocca and D. J. Duquette, J. Mater. Sci., 29, 4294 (1994)

8. M. Day and T. Suprunchuk, J. Appl. Polym. Sci., 35, 529 (1988).

9. M. Banks, J. R. Ebdon, and M. Johnson, Polymer, 34, 4547 (1993).

10. D. W. McKee, in "Chemistry and Physics of Carbon," Vol. 16, P. L. Walker, Jr., Ed., Marcel Dekker Inc., New York, N.Y.,
1981, p 1.

11. E. J. Hippo, N. Murdic, and W. Kowbel, Carbon, 27, 331 (1989).

12. J. K. Mun, C. O. Park, B. I. Yoon, K. S. Kim, and H. J. Joo, J. Mater. Sci., 30, 1529 (1995).

13. D. Cho, Carbon, 34, 1151 (1996).

14. D. Cho, H. S. Kang, H. C. Park, H. S. Ha, B. I. Yoon, and K. S. Kim, Polymer (Korea), 20, 650 (1996).

15. S. Lehmann, C. Megerdigian, and R. Papalia, SAMPE Quant., April, 7 (1985).

16. L. Y. Yuan, S. S. Shyu, and J. Y. Lai, J. Appl. Polym. Sci., 42 2525 (1991).

17. M. Guigon and E. Klinklin, Composites, 25, 534 (1994).

18. D. Cho, J. Y. Lee, and B. I. Yoon, J. Mater. Sci. Lett., 12, 1894 (1993).

19. J.-B. Donnet and R. C. Bansal, in "Carbon Fibers," Mercel Dekker Inc., New York, N.Y., 1984, Chapter 2.

20. Y. Yin, J. G. P. Binner, T. E. Cross, and S. J. Marshall, J. Mater. Sci., 29, 2250 (1994).

21. D. L. Gin, J. K. Avlyanov, Y. Min, and A. G. MacDiarmid, Polym. Prepr., Am. Chem. Soc., Div. Polym. Chem., 35(1), 287 (1994) 